\title{
ANXIETY DISORDERS - ASSESSMENT AND MANAGEMENT IN GENERAL PRACTICE
}

Dr Kwek Thiam Soo

\section{ABSTRACT}

The objective of this article is to provide an update on the diagnosis, assessment, and management of anxiety disorders in adults. This article covers the following disorders: panic disorder, panic attacks, specific phobia, social anxiety disorder and generalized anxiety disorder. Selective mutism and separation anxiety disorder, being childhood anxiety disorders, will not be covered. 0 bsessive compulsive disorder and post-traumatic stress disorder, which are not categorized as anxiety disorders in DSM-5, will not be covered.

Anxiety and related disorders are common mental health disorders but are under-diagnosed and undertreated. Most cases of anxiety disorders present first to the primary care physician and can be managed in primary care.

It is important to take a detailed history of the patient's symptoms and their severity and duration, enquire about psychosocial stressors, as well as symptoms that may be suggestive of a medical condition and also to assess suicidality. A combined approach of psychoeducation, relaxation training, and medications give the best results. SSRIs are first line pharmacologic treatment for most anxiety disorders. There is a need to stress that benzodiazepines have no role in the longterm treatment of anxiety disorders. They should not be given for more than 2 to 4 weeks. T reatment for generalized anxiety disorder should be for at least 32 weeks as high relapse rates are reported after discontinuing medications.

Keywords: DSM-5; panic disorder; panic attacks; specific phobia;social anxiety disorder; generalized anxiety disorder;

\section{SFP2021; 47(4) : 6-12}

\section{INTRODUCTION}

The objective of this article is to provide an update on the diagnosis, assessment and management of anxiety disorders in adults.

In the progression from DSM-IV to the present DSM-5 (2013), the anxiety disorders of the former DSM-IV have been organized into 3 separate categories in DSM-5. ${ }^{1}$ These are:

1-Anxiety disorders (separation anxiety disorder, selective mutism, specific phobia, social phobia, panic disorder,

Kwek Thiam Soo

Family Physician

Bukit Batok Medical Clinic agoraphobia, and generalized anxiety disorder).

2-Obsessive-compulsive disorders (obsessive-compulsive disorder, body dysmorphic disorder, hoarding disorder, trichotillomania, and excoriation disorder).

3-Trauma and stress-related disorders (reactive attachment disorder, disinhibited social engagement disorder, PTSD, acute stress disorder, and adjustment disorder).

The focus of this article is on anxiety disorders in adults and only the following will be covered: panic disorder and panic attacks; agoraphobia; social anxiety disorder (SAD); and generalized anxiety disorder (GAD).

Three recently published CPGs on anxiety disorders were reviewed namely, the Australian New Zealand guideline $(2018)^{2}$, the Singapore $\mathrm{MOH}$ guideline $(2015)^{3,4}$, and the Canadian guideline $(2014)^{5}$. Useful and new information from these guidelines have been included into this article where relevant.

The DSM-5 diagnostic criteria of anxiety disorders have been included in the appendix of this article as an aide memoire.

The Mental Health Situation in Singapore

The key findings from the Singapore Mental Health Survey (SMHS) 2016 and published in $2019^{8}$ show that:

- One in seven people in Singapore has experienced a mood, anxiety or alcohol use disorder in their lifetime. The lifetime prevalence and 12-month prevalence breakdown by type of disorder is shown in Table 1.

- Among the conditions assessed in this study, Major Depressive Disorder (MDD), alcohol abuse and ObsessiveCompulsive Disorder (OCD) emerged as the top three mental disorders in Singapore.

- MDD was the most common with one in 16 people in Singapore having had the condition at some point in their lifetime, while alcohol abuse and OCD affected one in 24 and one in 28 people, respectively.

- Socio-demographic characteristics such as age, gender, ethnicity, marital status, education, employment and income status were factors associated with the prevalence of mental disorders.

- The proportion of the people with mental disorders who were not seeking help remains high, and a significant treatment gap remains. 


\section{Table 1. Lifetime and 12 month - prevalence of mental disorders, Singapore 2016 and 2010 compared}

\begin{tabular}{|c|c|c|c|c|}
\hline \multirow[t]{2}{*}{ Mental Disorder } & \multicolumn{2}{|c|}{ Lifetime prevalence } & \multicolumn{2}{|c|}{12 month prevalence } \\
\hline & $\begin{array}{l}\text { SMHS } \\
2010(\%)\end{array}$ & \begin{tabular}{|l} 
SMHS \\
$2016(\%)$
\end{tabular} & $\begin{array}{l}\text { SMHS } \\
2010 \text { (\%) }\end{array}$ & $\begin{array}{l}\text { SMHS } \\
2016(\%)\end{array}$ \\
\hline $\begin{array}{l}\text { Major depressive } \\
\text { disorder }\end{array}$ & 5.8 & 6.3 & 2.2 & 2.3 \\
\hline Bipolar disorder & 1.2 & 1.6 & 0.6 & 0.9 \\
\hline $\begin{array}{l}\text { Generalized anxiety } \\
\text { disorder* }\end{array}$ & 0.9 & 1.6 & 0.4 & 0.8 \\
\hline $\begin{array}{l}\text { Obsessive compulsive } \\
\text { disorder }\end{array}$ & 3.0 & 3.6 & 1.1 & 2.9 \\
\hline Alcohol abuse* & 3.1 & 4.1 & 0.5 & 0.6 \\
\hline Alcohol dependence & 0.5 & 0.5 & 0.3 & 0.2 \\
\hline $\begin{array}{l}\text { Any of the above } \\
\text { mental disorders* }\end{array}$ & 12 & 13.9 & 4.4 & 6.4 \\
\hline $\begin{array}{l}\text { Comorbidity } \\
\text { (presence of two or } \\
\text { more of the above } \\
\text { mental disorders in } \\
\text { the same period) }\end{array}$ & 2.5 & 3.5 & 0.9 & 1.3 \\
\hline
\end{tabular}

Comparing the results of the 2016 SMHS study with the 2010 SMHS study, it was observed that:

- There was an increase in lifetime prevalence of mental illness from 12 percent in 2010 to 13.9 percent in 2016.

- The lifetime prevalence of almost all mental disorders showed an increase. However, the increase was statistically significant only for generalized Anxiety Disorder (GAD) and alcohol abuse.

- While there was no significant change in the proportion of people with a mental illness in their lifetime who did not seek help, persons who sought help had done so earlier.

\section{Definition of anxiety}

Anxiety may be defined as a mood state characterized by worry, apprehension and physical symptoms. It is used to describe the physical and psychological response to a feared situation. Anxiety is a normal human physiological mechanism designed to help the body respond to a threat. It arises in response to the perception of a threat to our well-being.

Anxiety serves a useful protective function in that it helps us to either tackle the source of the threat or to run away from it - the so-called "fight or flight response". The autonomic changes that occur in anxiety are essential to avoid danger. Moderate anxiety can actually improve performance. However, anxiety symptoms can also get out of hand, impairing one's usual functioning and leading to the development of an anxiety disorder ${ }^{6-7}$.

\section{Symptoms of anxiety}

Anxiety involves both physical and mental responses, manifesting as physical and psychological symptoms ${ }^{6}$. (Table 2)

\section{Table 2: Physical and psychological symptoms of anxiety}

\begin{tabular}{|c|c|}
\hline Physical & Psychological \\
\hline - Dizziness, feeling light-headed & - Feeling tensed and nervous \\
\hline - Sensation of shortness of breath & - Worrying thoughts \\
\hline - Palpitations & - Insomnia/nightmares \\
\hline - Sweating & - Irritability \\
\hline - Trembling or shaking & - Poor concentration and memory \\
\hline - Feelings of choking & - Tiredness \\
\hline - Chest discomfort & - Restlessness \\
\hline - Nausea or abdominal distress & - Sexual dysfunction \\
\hline $\begin{array}{l}\text { - Paresthesia's (numbness or } \\
\text { tingling sensations) }\end{array}$ & \\
\hline Source: Lee, $2010^{6}$ (Adapted) & \\
\hline
\end{tabular}

\section{Diagnosis of Anxiety Disorder}

With such a wide array of symptoms, it may appear difficult to make a diagnosis of an anxiety disorder. Furthermore, these symptoms can also be caused by many other medical conditions.

The family physician, however, has the advantage of being able to see the patient over a period of time. It is important to take note of the symptoms that the patient presents with and consider an anxiety disorder when there is a constellation of different somatic symptoms which cannot be attributed to a physical or medical disorder. A probe into the psychological symptoms, such as, irritability, worrying thoughts and sleep disturbance may then make the diagnosis obvious.

\section{Patient Assessment}

When faced with a patient with symptoms of anxiety, how do we differentiate normal anxiety from an anxiety disorder?

The following provide an approach ${ }^{6}$ :

1 Is what the patient experiencing Pathological?

2 What is the Pattern of the symptoms described?

3 What are the present stressors and Problems faced by the patient?

4 What can I do Practically for the patient?

5 Is a Psychiatric referral necessary?

\section{Is what the patient experiencing Pathological?}

Anxiety becomes a disorder when:

- it is out of proportion to the danger or threat causing it

- it continues even when the danger or stimulus is no longer present

- it results in significant distress and impairment in social, academic, occupational or other important areas of functioning

- it leads to avoidant behaviour

It is important to exclude other conditions, both medical and psychiatric, which have associated anxiety symptoms. 


\section{Medical Conditions for Exclusion}

Medical conditions that can be associated with anxiety are shown in Table 3. These conditions may aggravate or mimic anxiety symptoms.

\section{Table 3: Medical conditions and medications associated with anxiety}

\begin{tabular}{|c|c|}
\hline Endocrine & $\begin{array}{l}\text { Hyperthyroidism; hypoglycaemia; adrenal } \\
\text { insufficiency; hyperadrenocorticism; } \\
\text { phaeochromocytoma. }\end{array}$ \\
\hline Cardiovascular & $\begin{array}{l}\text { Congestive heart failure; pulmonary embolism; } \\
\text { arrhythmia; mitral valve prolapse. }\end{array}$ \\
\hline Respiratory & $\begin{array}{l}\text { Asthma; chronic obstructive lung disease; } \\
\text { pneumonia }\end{array}$ \\
\hline Gastrointestinal & Irritable bowel syndrome; peptic ulcer. \\
\hline Hematological & Iron deficiency; vitamin B12 deficiency. \\
\hline Neurological & $\begin{array}{l}\text { Vestibular dysfunction; migraine; neoplasm; } \\
\text { temporal lobe; epilepsy. }\end{array}$ \\
\hline Medications & $\begin{array}{l}\text { Specific SSRIs are associated with an increase in } \\
\text { anxiety in the first two weeks; excessive stimulant } \\
\text { (including caffeine and nicotine) intake; alcohol or } \\
\text { drug withdrawal (e.g. benzodiazepine). }\end{array}$ \\
\hline \multicolumn{2}{|c|}{ Sources: Lee, $2010^{6}$; Kyrios et al, $2011^{7}$, Adapted. } \\
\hline
\end{tabular}

\section{What is the pattern of the symptoms described?}

The pattern of symptoms often gives a clue to the type of anxiety disorder the patient may have. (Table 4)

\section{Table 4: Types of anxiety disorders and key features}

\section{1-Panic disorder}

- Recurrent unexpected panic attacks, in the absence of triggers

- Persistent concern or worry about panic attacks and/or maladaptive behavior change

\section{2-Agoraphobia}

- Marked, unreasonable fear or anxiety about two (or more) of the following five situations:

1-Using public transportation;

2-Being in open spaces;

3-Being in enclosed spaces;

4- Standing in line or being in a crowd;

5- Being outside of the home alone

- Active avoidance of feared situation due to thoughts that escape might be difficult or help unavailable if panic-like symptoms occur

\section{3-Specific phobia}

- Marked, unreasonable fear or anxiety about a specific object or situation, which is actively avoided (e.g., flying, heights, animals, receiving an injection, seeing blood)

\section{4-Social anxiety disorder}

- Marked, excessive or unrealistic fear or anxiety about social situations in which there is possible exposure to scrutiny by others

- Active avoidance of feared situation

\section{5-Generalized anxiety disorder (GAD)}

- Excessive, difficult to control anxiety and worry (apprehensive expectation) about multiple events or activities (work difficulties or school performance);

- Accompanied by symptoms such as restlessness/feeling on edge, easily fatigued, difficulty concentrating, irritability, muscle tension, sleep disturbance.

\section{6-Substance/Medication-induced Anxiety Disorder}

- Panic attacks or anxiety is predominant in the clinical picture

- Symptoms developed during or soon after substance intoxication or withdrawal or after exposure to a medication

\section{7-Anxiety Disorder Due to Another Medical Condition}

- Panic attacks or anxiety is predominant in the clinical picture

- There is evidence from the history, physical examination or laboratory findings that the disturbance is the direct pathophysiological consequence of another medical condition

Source: Katzman et al, $2014^{5}$ Adapted

3. What are the present stressors and problems faced by the patient?

One question that comes to mind when dealing with any psychiatric disorder should be "why now?"

Patients usually present to us when their stressors go beyond their normal ability to cope.

When this happens, we need to understand the changes in the person's environment that have caused the de-compensation. While it is important to make the correct diagnosis so as to be able to prescribe the correct medical treatment, knowing the current stressors allows us to help the patient holistically and provide resources to the patient to help deal with the underlying issues.

\section{What can I do practically for the patient?}

\section{4-1 Psychological therapy}

Psychological treatment [Lim L., et al, 2015] ${ }^{4}$ for an anxious patient may be in the form of simple interventions that can be employed easily even in a busy clinic setting.

\section{a. Therapeutic alliance}

The establishment of a therapeutic relationship is key. This therapeutic alliance is vital to the process of emotional and psychological healing and sets the foundation for all subsequent interventions. The family physician is well-placed to do this as he/she has obtained the trust of the patient and his/her family through years of collaborative interaction. 


\section{b. Psychoeducation}

For a patient suffering from an anxiety disorder, an understanding of the underlying disorder can by itself be therapeutic. Patients are instantly reassured just by knowing, from you, that they have a recognisable and treatable condition.

Much can be achieved by just helping patients understand the nature and origin of their symptoms. Panic disorders are a good example where psycho-education about the illness can be very useful.

For example, in panic disorder, patients frequently think that their symptoms actually herald a heart attack. By educating the patient about the symptoms of a panic attack, the patient will be less fearful when an attack is imminent, thus alleviating the likelihood of triggering the crescendo of anxiety symptoms that follow.

c. Teaching relaxation skills and stress reduction strategies

- Stress reduction strategies:

- Deal with negative thoughts

- Diaphragmatic breathing

- Progressive muscle relaxation

- Encourage to exercise more

- Reduce alcohol and caffeine intake

- Stop smoking

- Involve family members. Utilize community/social resources

- Supportive counselling

- Cognitive Behavioural Therapy (CBT)

\section{4-2 Pharmacological therapy}

The mainstay of pharmacological treatment for anxiety are the antidepressants. These are effective in both anxiety disorders as well as in depression. In terms of efficacy, all the various antidepressants are about equal or close to equal at about at 60$70 \%$ of patients. They vary in their side effect profiles. All antidepressants also take on the average 2-4 weeks to take effect and this should be explained to patient at the outset (Lee, 20106).

Anti-depressants have 4 advantages - minimal addictive potential; no tolerance effects; have anti-anxiety effects even in the absence of depression; and have minimal withdrawal symptoms (Lee, $2010^{6}$ ).

\section{Table 5. Pharmacological agents for treatment of anxiety and related disorders}

\begin{tabular}{|l|l|l|}
\hline $\begin{array}{l}\text { Class } \\
\text { Generic name }\end{array}$ & Trade name(s) & Dose (mg/day) \\
\hline SSRIs & & \\
Escitalopram & Lexapro & $10-20$ \\
Fluoxetine & Prozac, Magrilan & $20-60$ \\
Fluvoxamine & Faverin, Luvox & $25-200$ \\
Paroxetine & Seroxat, Paxil & $25-75$ \\
Sertraline & Zoloft & $50-200$ \\
& & \\
\hline
\end{tabular}

\begin{tabular}{|l|l|l|}
\hline $\begin{array}{l}\text { SNRIs } \\
\text { Venlafaxine }\end{array}$ & $\begin{array}{l}\text { Effexor } \\
\text { Cymbalta }\end{array}$ & $75-225$ \\
\hline NaSSAs & & $15-45$ \\
Mirtazapine & Remeron & \\
\hline TCAs & & $25-150$ \\
Amitryptyline & Vanatrip & $25-150$ \\
Clomipramine & Anafranil & $25-150$ \\
Dothiepin & Prothiaden & $25-150$ \\
Imipramine & Tofranil & \\
\hline $\begin{array}{l}\text { Azapirones } \\
\text { Buspirone }\end{array}$ & BuSpar & \\
\hline Benzodiazepines & & $0.25-4$ \\
Alprazolam & Xanax & $0.25-4$ \\
Clonazepam & Rivotril & $2-20$ \\
Diazepam & Valium & $0.5-4$ \\
Lorazepam & Lorans & \\
\hline
\end{tabular}

\section{1-Selective serotonin reuptake inhibitors (SSRIs)}

These medications are the first line pharmacological agents used to treat anxiety disorders. They work by preventing the reuptake of serotonin $(5 \mathrm{HT})$ by the presynaptic nerve, thus maintaining higher levels of 5-HT in the synapse.

There is a paradoxical increase in anxiety levels during the first two weeks of starting treatment. The anxiolytic effect occurs after two to four weeks. Examples of SSRI's and their therapeutic dosages are listed in Table 5.

\section{2-Serotonin Noradrenaline Reuptake Inhibitors (SNRIs)}

These inhibit the reuptake of serotonin and noradrenaline into the pre-synaptic nerve endings. They have faster onset of action than the SSRI's and little interaction with other drugs. One example is Venlafaxine.

\section{3-Noradrenergic Specific Serotonergic Antidepressant (NaSSA)}

The only example in this class is mirtazapine. Its sedative effect is advantageous in patients with insomnia. It also increases appetite and leads to weight gain.

\section{4-Tricyclic Antidepressants (TCAs)}

These are also effective for anxiety disorders. They have unpleasant anti-cholinergic side-effects. Fatal arrhythmias occur with overdose.

\section{5- Anti-histamine with anxiolytic properties}

One example is hydroxyzine. The therapeutic dosage is $25-150$ $\mathrm{mg} /$ day.

\section{6-Benzodiazepines}

These are effective in reducing anxiety symptoms of GAD, panic disorder and phobias. Rapid onset of action. 
Biggest drawback - Chronic use is associated with significant potential problems including tolerance, dependence, withdrawal, relapse, rebound, interactions with other medications and adverse events.

Precautions - The patient should also be advised from the onset that this is not the definitive treatment for the anxiety disorder and it is only meant to provide symptom relief while awaiting the anti-depressant to take effect. Hence, Benzodiazepines should be restricted to short-term use (up to two weeks) when initiating treatment and should not be used as monotherapy. They should be given at the lowest possible dose and gradually tapered off because of its addictive potential. They are contraindicated in those with alcohol or substance abuse. Commonly used examples are Alprazolam, Clonazepam, Diazepam, and Lorazepam.

Pharmacological treatment pointers in anxiety disorders :

1 Start with an SSRI - an adequate dose should be used, adequate duration is eight to twelve months

2 It is okay to prescribe benzodiazepines (BZPs) but watch for abuse/ dependency. It is for use in the short term of 2 to 4 weeks only.

3 Listen actively and give simple problem-solving advice.

4 Encourage relaxation, stress reduction.

5 Review regularly - weekly to bi-weekly for first two to three sessions and monthly to bi-monthly subsequently

Recommendations for pharmacotherapy and psychotherapy in the various anxiety disorders are given in Tables 6 to 9 .

\section{Table 6: Recommendations for pharmacotherapy and psychotherapy for panic disorder}

\begin{tabular}{|c|c|}
\hline First-line & $\begin{array}{l}\text { Either selective serotonin reuptake inhibitors } \\
\text { (SSRIs) or venlafaxine should be used }{ }^{4.5} \text {. }\end{array}$ \\
\hline Second-line & Imipramine and clomipramine are effective ${ }^{4}$. \\
\hline $\begin{array}{l}\text { Adjunctive } \\
\text { therapy }\end{array}$ & $\begin{array}{l}\text { Benzodiazepines may be added to } \\
\text { antidepressants in the short term to produce } \\
\text { a more rapid therapeutic response in the } \\
\text { treatment of panic disorder. In view of the } \\
\text { addictive potential, benzodiazepines should } \\
\text { be tapered and withdrawn by } 4 \text { weeks. }\end{array}$ \\
\hline $\begin{array}{l}\text { Not } \\
\text { recommended }\end{array}$ & $\begin{array}{l}\text { Buspirone, propranolol, tiagabine, } \\
\text { trazodone }^{5}\end{array}$ \\
\hline \multicolumn{2}{|c|}{ Source: Lim L., et al, 2015' Canadian guideline, $2014^{5}$} \\
\hline
\end{tabular}

Table 7: Recommendations for pharmacotherapy and psychotherapy in specific phobia

\begin{tabular}{|l|l|}
\hline First-line & $\begin{array}{l}\text { CBT should be used as first-line treatment } \\
\text { for specific phobias. }\end{array}$ \\
\hline $\begin{array}{l}\text { Adjunctive } \\
\text { therapy }\end{array}$ & $\begin{array}{l}\text { Benzodiazepines may be used on a short- } \\
\text { term basis for temporary relief in specific } \\
\text { phobia, pending resolution of symptoms } \\
\text { with other forms of treatment. }\end{array}$ \\
\hline Source: $\operatorname{Lim}$ L & et al $2015^{4}$ \\
\hline
\end{tabular}

\section{Table 8: Recommendations for pharmacotherapy and psychotherapy for social anxiety disorder}

\begin{tabular}{|l|l|}
\hline First-line & $\begin{array}{l}\text { Either pharmacotherapy or psychotherapy } \\
\text { alone may be used as first-line treatment } \\
\text { for SAD, depending on patient preferences, } \\
\text { values and economic considerations. } \\
\text { Either SSRIs or venlafaxine should be used } \\
\text { as first-line pharmacotherapy for SAD }\end{array}$ \\
\hline Second-line & $\begin{array}{l}\text { Moclobemide may be used for the } \\
\text { treatment of SAD if treatment with SSRIs or } \\
\text { venlafaxine has not been effective. }\end{array}$ \\
\hline $\begin{array}{l}\text { Adjunctive } \\
\text { therapy }\end{array}$ & $\begin{array}{l}\text { Benzodiazepines may be used on a short- } \\
\text { term for temporary anxiety relief pending } \\
\text { resolution of phobic symptoms with other } \\
\text { forms of treatment. }\end{array}$ \\
\hline $\begin{array}{l}\text { Not } \\
\text { recommended }\end{array}$ & $\begin{array}{l}\text { Beta-blockers (e.g., atenolol, propranolol) } \\
\text { are not recommended for the treatment of } \\
\text { SAD, as they have been found ineffective. } \\
\text { However, they may be used for the } \\
\text { treatment of performance anxiety (e.g., } \\
\text { playing an instrument, giving a speech). }\end{array}$ \\
\hline Source: Lim L., et al, 2015 \\
\hline
\end{tabular}

\section{Table 9: Recommendations for pharmacotherapy and psychotherapy for generalised anxiety disorder}

\begin{tabular}{|c|c|}
\hline First-line & $\begin{array}{l}\text { Either SSRIs or venlafaxine should be used } \\
\text { as first-line pharmacological treatment } \\
\text { for GAD. CBT may be used as first-line } \\
\text { psychotherapy treatment for GAD } \\
\text { Drug treatment for GAD needs to be } \\
\text { continued for at least } 32 \text { weeks as high } \\
\text { relapse rates are reported after } \\
\text { discontinuing medications }\end{array}$ \\
\hline Second-line & $\begin{array}{l}\text { Imipramine may be considered a second- } \\
\text { line treatment for GAD, in view of the } \\
\text { possibility of poor tolerability and danger of } \\
\text { fatal over dosage } \\
\text { Mirtazapine may be considered a second- } \\
\text { line treatment for GAD due to its anxiolytic } \\
\text { effects }\end{array}$ \\
\hline $\begin{array}{l}\text { Adjunctive } \\
\text { therapy }\end{array}$ & $\begin{array}{l}\text { Hydroxyzine may be used as adjunctive } \\
\text { treatment together with other anxiolytic } \\
\text { agents for treatment of GAD. }\end{array}$ \\
\hline $\begin{array}{l}\text { Not } \\
\text { recommended }\end{array}$ & $\begin{array}{l}\text { Benzodiazepines should not be used for the } \\
\text { long term treatment of GAD } \\
\text { Propranolol is not recommended for the } \\
\text { long term treatment of generalised anxiety } \\
\text { disorder. }\end{array}$ \\
\hline
\end{tabular}


5) Is a Psychiatric referral necessary?

Most patients with anxiety disorders such as GAD and panic disorder can be managed in a general practice setting.

Patients should be referred when:

- symptoms are severe or complex

- symptoms fail to improve with initial treatment and follow-up

- co-occurring drug/alcohol abuse

- there are psychotic symptoms

- there is serious risk of suicide

\section{A ppendix 1. DSM-5 A nxiety disorders diagnostic criteria}

\section{Table A 1. Panic disorder DSM-5 diagnostic criteria}

The person has experienced both of the following:

- Recurrent unexpected panic attacks

- $\geq 1$ of the attacks followed by $\geq 1$ month of 1 or both of the following:

- Persistent concern or worry about additional panic attacks or their consequences

- Significant maladaptive change in behavior related to the attacks

Source: Katzman et al, $2014^{5,9}$

\section{Table A2. DSM-5 criteria for panic attacks}

\section{A panic attack is defined as:}

An abrupt surge of intense fear or intense discomfort that reaches a peak within minutes, and includes $\geq 4$ of the following symptoms:

(1) Palpitations, pounding heart, or accelerated heart rate

(2) Sweating

(3) Trembling or shaking

(4) Sensations of shortness of breath or smothering

(5) Feelings of choking

(6) Chest pain or discomfort

(7) Nausea or abdominal distress

(8) Feeling dizzy, unsteady, light-headed, or faint

(9) Chills or heat sensations

(10) Paresthesia (numbness or tingling sensations)

(11) Derealization (feelings of unreality) or depersonalization (being detached from oneself)

(12) Fear of losing control or going crazy

(13) Fear of dying.

Source: Katzman et al, $2014^{5,9}$
Table A 3. Specific phobia specifiers

\begin{tabular}{|l|l|}
\hline Specifier & Examples \\
\hline Animal & Spiders, insects, dogs \\
\hline Natural environment & Heights, storms, water \\
\hline Blood-injection-injury & $\begin{array}{l}\text { Needles, invasive medical } \\
\text { procedures }\end{array}$ \\
\hline Situational & $\begin{array}{l}\text { Airplanes, elevators, enclosed } \\
\text { spaces }\end{array}$ \\
\hline Other & $\begin{array}{l}\text { Choking or vomiting; In children } \\
- \text { loud sounds or costumed } \\
\text { characters }\end{array}$ \\
\hline Source: Katzman et al, $20144^{5,9}$ \\
\hline
\end{tabular}

\section{Table A 4. A goraphobia DSM-5 diagnostic criteria}

- Marked fear or anxiety about $\geq 2$ of the following 5 groups of situations:

(1) Public transportation (e.g., traveling in automobiles, buses, trains, ships, or planes)

(2) Open spaces (e.g., parking lots, market places, or bridges)

(3) Being in shops, theatres, or cinemas

(4) Standing in line or being in a crowd

(5) Being outside of the home alone in other situations

- The individual fears or avoids these situations due to thoughts that escape might be difficult or help might not be available in the event of panic-like symptoms

- The agoraphobic situations almost always provoke fear or anxiety

- The situations are actively avoided, require presence of a companion, or endured with marked fear or anxiety

- The fear or anxiety is out of proportion to actual danger posed by agoraphobic situation

- The fear, anxiety, or avoidance is persistent, typically lasting $\geq 6$ months

- The fear, anxiety, and avoidance cause clinically significant distress or functional impairment

Source: Katzman et al, $2014^{5,9}$ 


\section{Table A 5. Social anxiety disorder DSM-5 diagnostic criteria}

- Marked fear or anxiety about social situations in which the person may be exposed to scrutiny by others

- Fear that actions or showing anxiety symptoms will cause negative evaluation (e.g., embarrassment, humiliation) or offend others

- The social situation: almost always provokes fear or anxiety; and is actively avoided or endured with marked fear or anxiety

- The fear, anxiety, or avoidance: is out of proportion to the actual threat posed by the social situation; is persistent, typically $\geq 6$ months; and causes significant distress or functional impairment

- If another medical condition is present (e.g., stuttering, obesity), the disturbance is unrelated or out of proportion to it

- Specify "performance only" if the fear is restricted to speaking or performing in public.

Source: Katzman et al, 2014 5,9

\section{Table A6. generalized anxiety disorder - DSM-5 diagnostic criteria}

- Excessive anxiety and worry (apprehensive expectation) about a number of events or activities (e.g., school/work performance)

- The individual finds it difficult to control the worry

- Excessive anxiety and worry are associated with $\geq 3$ of the following symptoms (with at least some occurring more days than not for $\geq 6$ months): restlessness or feeling keyed-up or on edge; being easily fatigued; difficulty concentrating; irritability; muscle tension; or sleep disturbance

- The disturbance causes clinically significant distress or functional impairment.

Source: Katzman et al, $2014^{5,9}$

\section{REFEREN CES}

1. Mentalhelp.Net. The new DSM-5: Anxiety disorders and obsessive compulsive disorders. [Internet] American Addiction Centres; 2019. [Accessed 20 Jun 2019]. Available from:

https://www.mentalhelp.net/anxiety/and-obsessive-compulsive-disorders-new-dsm-5/

2. Andrews G, Bell C, Boyce P, Gale C, Lampe L, Marwat O, Rapee R, Wilkins G. Royal Australian and New Zealand College of Psychiatrists clinical practice guidelines for the treatment of panic disorder, social anxiety disorder and generalised anxiety disorder. [Internet] Australian \& New Zealand Journal of Psychiatry. 2018 Dec; 52(12):1109-72. [Accessed 20 Jun 2019]. Available from:https://journals.sagepub.com/doi/10.1177/0004867418799453

3. Lim L, Chan HN, Chew PH, Chua SM, Ho C, Kwek SK, Lee TS, Loh P, Lum A, Tan YH, Wan YM. Ministry of Health clinical practice guidelines: Anxiety disorders. Singapore medical journal. 2015 Jun; 56(6):310. PMID: 26106237.

4. Lim L, Chan HN, Chew PH, Chua SM, Ho C, Kwek SK, Lee TS, Loh P, Lum A, Tan YH, Wan YM. Ministry of Health clinical practice guidelines: Anxiety disorders. Singapore medical journal. 2015 Jun; 56(6):310

5. Katzman MA, Bleau P, Blier P, Chokka P, Kjernisted K, Van Ameringen M. Canadian clinical practice guidelines for the management of anxiety, posttraumatic stress and obsessive-compulsive disorders. BMC psychiatry. 2014 Jul; 14(1):S1.PMID:25081580.

6. Nelson Lee. Anxiety Disorders: An Approach with Focus on Panic Disorder and Generalised Anxiety Disorder. The Singapore Family Physician. 2010; 36(1):22-5.

7. Kyrios M, Mouding R, Nedelikovic M. Anxiety disorders: Assessment and management in general practice. Australian family physician. 2011 Jun; 40(6):370-4.

8. Subramaniam M, Abdin E, Vaingankar JA, Shafie S, Chua BY, Sambasivam R, Zhan YJ, Shahwan S, Chang S, Chua HC, Verma S, James L, Kwok KW, Heng D, Chong SA Tracking the mental health of a nation: prevalence and correlates of mental disorders in the second Singapore mental health study. Epidemiol Psychiatr Sci. 2019 Apr 5:1-10. PMID: 30947763 .

9. American Psychiatric Association. Diagnostic and statistical manual of mental disorders (DSM-5 ${ }^{\circ}$ ). American Psychiatric Pub; 2013 May 22.

\section{LEARN IN G POINTS}

- Anxiety disorders are common mental health disorders but are under-diagnosed and undertreated.

- Most cases of anxiety disorders are presented first to the primary care physician and can be managed in primary care.

- Take a good history of patient's symptoms, severity, duration, presence of psychosocial stressors, medical problems, and also assess suicidality.

- A combined approach of psycho-education, relaxation training and medications give the best results.

- SSRIs are first-line pharmacologic treatment for most anxiety disorders.

- It is important to note that benzodiazepines has no role for long term treatment.

- Treatment for generalized anxiety disorder should be for at least 32 weeks as high relapse rates are report after discontinuing medications. 